\title{
DESAIN SABO DAM TIPE CONDUIT SEBAGAI PENGENDALI DAYA RUSAK ALIRAN DEBRIS
}

\author{
Yuli Fajarwati ${ }^{1,4}$, Teuku Faisal Fathani ${ }^{2,4}$, Fikri Faris ${ }^{2,4}$, Wahyu Wilopo ${ }^{3,4}$ \\ ${ }^{1}$ Magister Teknik Sipil, Departemen Teknik Sipil dan Lingkungan Fakultas Teknik UGM; \\ ${ }^{2}$ Departemen Teknik Sipil dan Lingkungan Fakultas Teknik UGM; \\ ${ }^{3}$ Departemen Teknik Geologi Fakultas Teknik UGM \\ ${ }^{4}$ Pusat Unggulan dan Inovasi Teknologi Mitigasi Kebencanaan UGM (GAMA-InaTEK) \\ Email:yulifajarwati@gmail.com
}

\begin{abstract}
ABSTRAK
Sungai Air Kotok di Kabupaten Lebong, Bengkulu memiliki litologi batuan yang rapuh akibat pengaruh panas bumi, kondisi tersebut menyebabkan rentan mengalami pergerakan massa tanah/batuan. Oleh karena itu, diperlukan upaya mitigasi untuk mengurangi risiko bencana dengan perencanaan bangunan pengendali aliran debris berupa sabo dam. Penelitian ini bertujuan untuk merencanakan desain sabo dam tipe conduit yang dirancang secara seri dan mengevaluasi stabilitas sabo dam berdasar SNI 2851:2015. Hasil perhitungan menunjukkan debit puncak untuk kala ulang 100 tahun sebesar $171,21 \mathrm{~m}^{3} /$ detik. Empat seri sabo dam memiliki dimensi lebar pelimpah rerata $\pm 40 \mathrm{~m}$, kedalaman aliran debris sebesar $1 \mathrm{~m}$, dan tinggi pelimpah ialah $2,4 \mathrm{~m}$. Stabilitas sabo dam saat banjir diperoleh faktor aman untuk stabilitas geser dan guling sebesar 3,$46 ; 1,62$. Adapun faktor aman terhadap pengaruh aliran debris untuk stabilitas geser dan guling adalah 3,$30 ; 1,58$. Berdasarkan hasil analisis, empat seri sabo dam tipe conduit yang dirancang mampu mengendalikan daya rusak banjir maupun aliran debris.
\end{abstract}

Kata kunci: Hidraulika sungai, aliran sedimen, bangunan sabo, stabilitas sabo

\begin{abstract}
Air Kotok River in Lebong Regency, Bengkulu Province has the lithology of weathered rock which is a result of geothermal process, this condition causes to be susceptible to land / rock mass movements. Therefore, the mitigation efforts are needed to reduce the risk from disaster by design debris flow control such as sabo dam. This study aims to design series of conduit type sabo dam and evaluate the stability based on SNI 2851: 2015. The calculation shows that the peak discharge for the 100-year return period is $171.21 \mathrm{~m}^{3} / \mathrm{sec}$. The four sabo dam series have dimensions of spill width of $\pm 40 \mathrm{~m}$, debris flow depth of $1 \mathrm{~m}$, and overflow height of $2.4 \mathrm{~m}$. The stability of sabo dam has safety factor in flood condition for shear and overturning stability are 3.46; 1.62, while in a debris flow condition for shear and overturning stability are 3.30; 1.58. Based on the results, the four series of conduit sabo dam are able to control the destructive power of floods and debris flows.
\end{abstract}

Key word: River hydraulic, sediment flow, sabo building, stability of sabo 


\section{PENDAHULUAN}

Peristiwa gempa yang disertai hujan dengan intensitas tinggi pada beberapa tahun terakhir memicu terjadinya longsor di Bukit Beriti Besar dan diikuti banjir bandang di Kabupaten Lebong, Provinsi Bengkulu. Sumber longsoran berasal dari Bukit Beriti Besar yang merupakan hulu Sungai Air Kotok. Berdasarkan hasil pengamatan, kejadian ini membawa material longsoran berupa bongkahan batu dan pohon, sehingga merusak beberapa fasilitas di sekitar Sungai Air Kotok seperti jalan akses dan jembatan. Secara umum, kejadian tersebut merupakan aliran debris. Kejadian aliran debris pada tahun 2018 menunjukkan perubahan penampang Sungai Air Kotok menjadi lebih luas, selain itu terdapat jalur aliran baru yang disebabkan oleh beberapa kejadian banjir.

Karakteristik di hulu Sungai Air Kotok memiliki lembah sungai berbentuk "V" dengan penampang yang sempit dan lembah yang dalam. Apabila terjadi gerakan massa yang meluncur dan terendapkan, material longsoran dapat menjadi bendung alam. Menurut Turnbull dkk. (2015) dan Takahashi (2007), aliran debris dipengaruhi oleh kondisi alam, seperti kemiringan lereng, jenis batuan/tanah, kondisi struktur geologi, hidrologi lereng, dan tata guna lahan. Aliran debris dapat bergerak dengan kecepatan aliran mulai dari rendah sampai sangat tinggi, sehingga material yang terbawa dapat tergerus selama pergerakan ke bawah lereng (Hardiyatmo, 2012).

\section{METODE PERANCANGAN}

Kajian bencana sedimen dan desain sabo dam dilakukan di Daerah Aliran Sungai (DAS) Air Kotok, Kabupaten Lebong, Provinsi Bengkulu (Gambar 1). Ditinjau dari aspek tektonik, lokasi penelitian merupakan daerah yang rawan mengalami gempa bumi, sehingga menyebabkan kondisi batuan penyusun lereng tidak stabil dan rawan longsor. Apabila terjadi hujan dengan intensitas tinggi, material longsor akan menjadi aliran debris yang mengarah ke badan Sungai Air Kotok.

Morfologi yang berkembang pada daerah hilir Sungai Air Kotok merupakan sungai teranyam (braided stream). Sungai teranyam terbentuk pada daerah berlereng landai dengan batuan penyusun yang bersifat lunak seperti endapan. Sungai teranyam memiliki alur sungai menyebar pada hilir sungai, sehingga menyebabkan aliran sungai mudah berbelok dari aliran sungai utama.

Menurut Fathani dan Wilopo (2018), kondisi geomorfologi Sungai Air Kotok dan sekitarnya terbagi menjadi lima satuan, yaitu satuan dataran kipas aluvial, satuan dataran berlereng landai, satuan perbukitan berlereng landai, satuan perbukitan berlereng sedang, dan satuan perbukitan berlereng curam. Secara umum, Sungai Air Kotok berada pada satuan kipas aluvial, satuan perbukitan berlereng curam dan satuan perbukitan berlereng landai. Berdasarkan karakteristik batuan di lapangan, litologi yang berkembang pada Sungai Air Kotok dan sekitarnya adalah batuan vulkanik yang terdiri dari lava andesit dan breksi andesit, serta endapan debris berukuran pasir dengan fragmen batuan berukuran sedang hingga bongkahan besar.

Data-data yang digunakan pada kajian ini diperoleh dari data primer dan sekunder. Data-data yang dimaksud antara lain data topografi, data curah hujan, dan peta geologi. Perancangan bangunan sabo dam mengacu pada standar peraturan Japan International Cooperation Agency (JICA, 2010) dan analisis stabilitas struktur sabo dam mengacu pada SNI 2851:2015. 
Analisis hidrologi dalam penelitian ini menggunakan metode Hidrograf Satuan Sintetis (HSS) dengan data topografi yang diperoleh dari citra LiDAR. Kemudian, analisis geoteknik dilakukan untuk menentukan stabilitas sabo dam menggunakan data yang diperoleh dari hasil pengujian lapangan dan pengujian laboratorium.

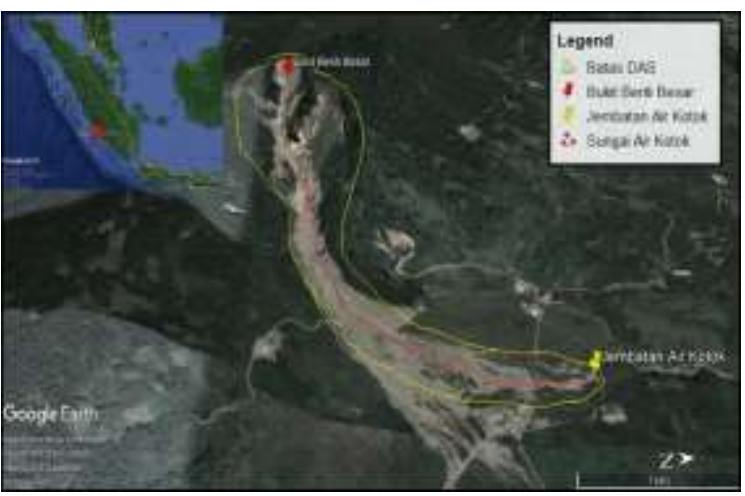

Gambar 1. Lokasi Penelitian (Google Earth, diakses pada April 2019)

\section{HASIL DAN PEMBAHASAN}

Hilir DAS Air Kotok dan sekitarnya membentuk kondisi geologi berupa kipas aluvial hasil endapan sedimen akibat aliran debris. Berdasarkan Kajian Ancaman Aliran Debris Bukit Beriti Besar dan Sungai Air Kotok (Fathani dan Wilopo, 2018), daerah dari hulu sungai hingga ke Jembatan Sungai Air Kotok merupakan bagian dari upper fan, dimana daerah ini cocok untuk penempatan struktur pengendali aliran debris. Desain sabo dam di daerah pegunungan lebih ditekankan pada upaya pencegahan bencana aliran debris pada daerah aliran sungai (Ministry of Land Infrastructure and Transport of Japan, 2004). Sabo dam didesain berdasarkan bentuk geometri dan letak bottle neck sungai yang dibangun pada titik hulu daerah tangkapan debris untuk mencegah laju aliran debris ke hilir sungai. Struktur sabo dam yang direncanakan dalam kajian ini berfungsi untuk menahan sebagian material bergradasi kasar, mengurangi kecepatan aliran, dan mengarahkan aliran debris ke tengah palung sungai agar tidak mengerosi tebing sungai.

\section{Desain Sabo Dam}

Ditinjau dari mekanisme pengendalian aliran debris, sabo dam diklasifikasikan menjadi 2 jenis, yaitu sabo dam jenis tertutup dan sabo dam jenis terbuka (Kim dkk., 2014 ; Zou dan Chen, 2015). Sabo dam tipe tertutup merupakan suatu struktur dinding tertutup yang sangat efektif dalam menahan, menampung, dan mengurangi aliran sedimen. Namun, apabila daya tampung sudah penuh dengan sedimen, fungsi utama sabo dam hanya sebagai penahan laju debit puncak sedimen, sehingga ketika terjadi banjir aliran debris sedimen/lahar yang membahayakan, kemampuan sabo dam dalam mengendalikan daya rusak sudah terbatas. Sabo dam tipe terbuka dapat menahan sebagian material debris bergradasi kasar, sehingga kecepatan aliran berkurang dan daya rusak juga berkurang. Bangunan sabo dan tipe terbuka mengarahkan aliran debris ke tengah palung sungai agar tidak mengerosi tebing sungai dan mengalirkan kembali material (pasir dan kerikil) ke daerah hilir untuk menjaga keseimbangan sedimen agar tidak terjadi degradasi dasar sungai (Hassan, 2019).

Berdasarkan SNI 2851:2015 tentang Desain Bangunan Penahan Sedimen, penanggulangan bencana akibat aliran sedimen berlebih seperti aliran lahar dan aliran debris adalah dengan penerapan teknologi sabo dam. Penentuan lokasi sabo dam mempertimbangkan beberapa hal berikut:

1. Geometri dan topografi Sungai Air Kotok.

2. Kondisi geologi tanah dan batuan di Sungai Air Kotok, dimana batuan dasar terletak sangat dalam dan bagian permukaan terdiri dari material batu pasir, batu kerikil, dan batuan aluvial. Lokasi sabo dam idealnya ditempatkan 
setelah tekuk lereng, sehingga bangunan sabo dam tidak terhantam langsung oleh material debris. Tekuk lereng dapat meredam energi akibat benturan debris, sehingga energi yang harus ditahan oleh sabo dam menjadi lebih kecil. Sabo dam tipe seri akan bekerja efektif apabila ditempatkan antara zona sumber material sampai zona transportasi (Armanini dkk. 2014). Skema sistem sabo dam seri dapat dilihat pada Gambar 2.

3. Kondisi lingkungan dan kemudahan pelaksanaan konstruksi. Pelaksanaan konstruksi sabo dam mempertimbangkan ketersediaan dan kemudahan material untuk konstruksi (SNI 1724:2015).

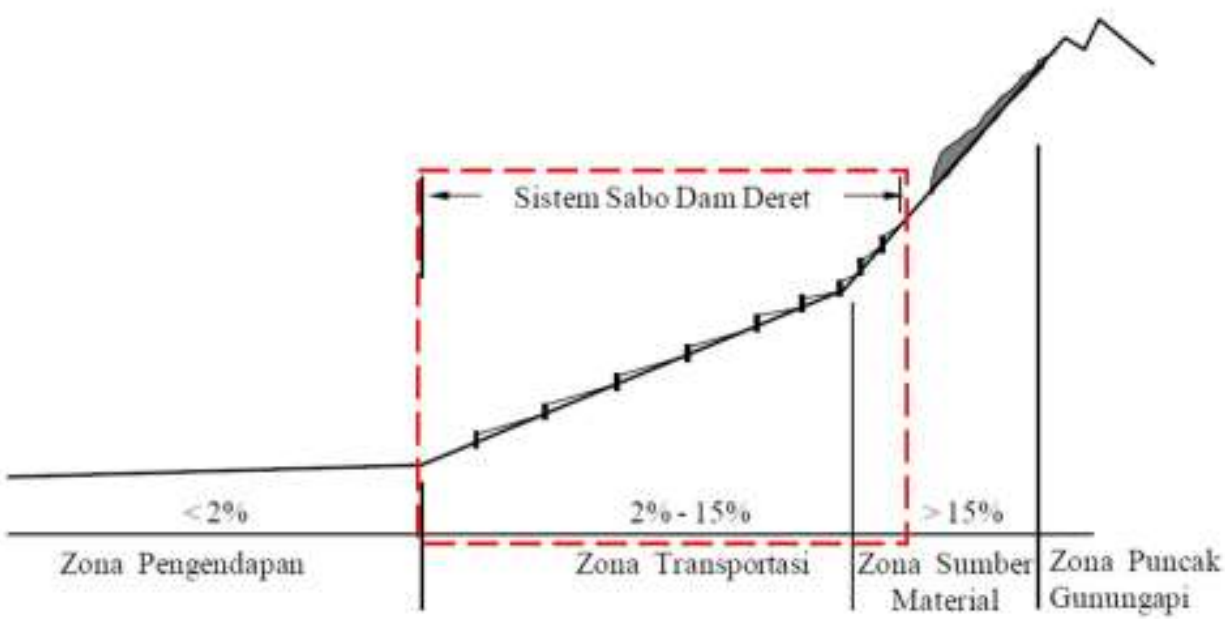

Gambar 2. Skema Sistem Sabo Dam Seri

(Pusat Penelitian dan Pengembangan Sumber Daya Air, 2014)

Penentuan jumlah sabo dam di Sungai Air Kotok mempertimbangkan panjang keseluruhan sungai dan jarak antar sabo dam. Chatwin, dkk. (1994) menyarankan persamaan untuk menghitung jarak antar sabo seperti pada persamaan 1 sebagai berikut.

$$
L_{2}>\frac{H}{\tan \left(\theta-\theta_{e}\right)}
$$

dengan tinggi sabo dam $(H)$, kemiringan dasar sungai $(\theta)$, kemiringan dasar sungai dinamis $\left(\theta_{e}\right)$ dan jarak antara sabo dam satu dengan lainnya $\left(L_{2}\right)$.

Berdasarkan persamaan (1), diperoleh jarak antar sabo dam sepanjang $300 \mathrm{~m}$. Hasil perhitungan tersebut dijadikan acuan jumlah sabo dam yang ditempatkan di zona sumber material dan zona transportasi, sehingga dapat ditentukan jumlah bangunan sabo dam sebanyak empat buah. Pemilihan tipe sabo dam mempertimbangkan beberapa hal berikut.

1. Karakteristik morfologi sungai, meliputi geometri sungai, citra satelit lokasi, dan koefisien kekasaran sungai.

2. Fungsi bangunan sabo dam.

Sungai Air Kotok merupakan sungai torensial dengan kemiringan dasar sungai yang curam dan debit aliran yang besar. Aliran air di sepanjang Sungai Air Kotok mengalir di sepanjang tahun. Bangunan sabo dam di lokasi penelitian difungsikan untuk menahan material debris agar tidak mengalir ke hilir dan merusak fasilitas umum, sehingga pemilihan sabo dam jenis terbuka (Gambar 3) sangat cocok pada lokasi penelitian ini. 


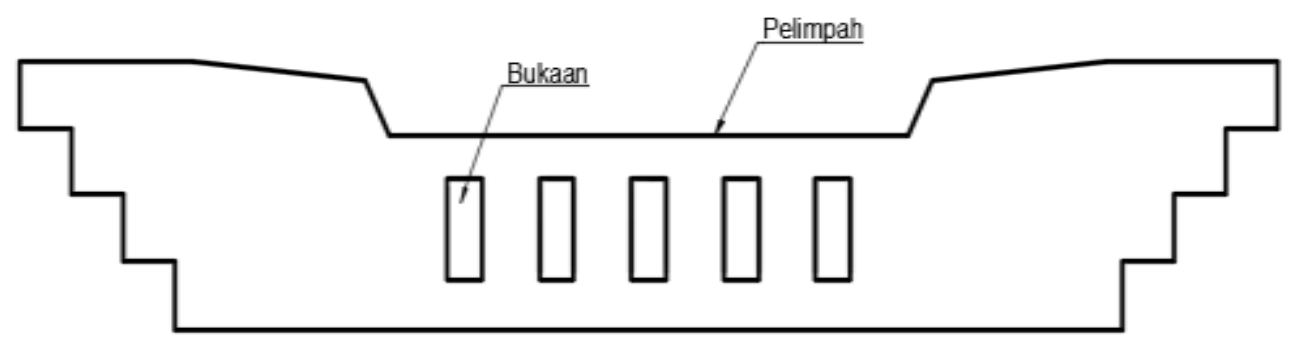

Gambar 3. Sabo Dam Jenis Terbuka Tipe Conduit

Tahap awal perencanaan sabo dam adalah menentukan debit banjir rencana $\left(Q_{p}\right)$ pada lokasi kajian. Kemudian, penentuan debit rencana aliran debris $(Q)$ dan debit puncak aliran debris $\left(Q_{s p}\right)$ yang akan digunakan sebagai parameter untuk menentukan dimensi sabo dam.

Perencanaan debit sabo dam ditentukan berdasarkan besarnya debit banjir maksimum pada periode ulang tertentu. Debit banjir rencana dihitung dengan metode Hidrograf Satuan Sintetis (HSS). Debit puncak aliran debris bergantung pada nilai konsentrasi endapan sedimen $\left(C^{*}\right)$, konsentrasi aliran debris $\left(C_{d}\right)$, dan debit rencana aliran debris $(Q)$. Nilai konsentrasi aliran debris dipengaruhi oleh massa jenis debris atau boulder $(\sigma)$, massa jenis air $(\rho)$, sudut gesek internal sedimen, dan kemiringan dasar sungai. Nilai massa jenis debris $(\sigma)$ ditentukan berdasarkan standar menurut Huang dkk. (2003) dan sudut gesek internal sedimen $(\phi)$.

Debit rencana aliran debris $(Q)$ dipengaruhi oleh nilai rasio konsentrasi sedimen $(\alpha)$ dan debit banjir rencana $\left(Q_{p}\right)$. Adapun nilai rasio konsentrasi aliran debris sebesar $50 \%$ dari debit banjir rencana. Nilai tersebut diambil karena adanya campuran air dan sedimen kasar maupun halus dalam aliran debris. Nilai debit banjir rencana $\left(Q_{p}\right)$ untuk kala ulang 100 tahun dengan metode HSS diperoleh nilai $114,14 \mathrm{~m}^{3} /$ det. Nilai debit banjir rencana $\left(Q_{p}\right)$ digunakan untuk menghitung nilai debit rencana aliran debris (Q) dengan memperhitungkan sudut aliran debris $(\alpha)$ menggunakan persamaan di bawah ini.

$$
Q=Q_{p} \times(1+\alpha)
$$

Berdasarkan persamaan (2) diperoleh nilai debit rencana aliran debris kala ulang 100 tahun sebesar 171,21 m³/det. Debit puncak aliran debris dihitung menggunakan persamaan berikut:

$$
Q_{s p}=\frac{C_{*}}{C_{*}-C_{d}} \times Q_{p}
$$

Dengan asumsi jika nilai $C_{d} 0,3$ dan nilai $C^{*}$ diambil 0,6 , diperoleh nilai debit puncak aliran debris $\left(Q_{s p}\right)$ sebesar $228,28 \mathrm{~m}^{3} /$ det.

Tinggi sabo dam direncanakan berdasarkan volume debris yang akan ditampung. Rencana volume debris ( $V$ ) yang akan ditampung adalah $40.000 \mathrm{~m}^{3}$. Untuk menghitung tinggi sabo dam, digunakan persamaan berikut:

$H=\left(\frac{V}{n . B}\right)^{0,5}$

Dengan kemiringan dasar sungai $(n)$ 0,1 dan lebar rerata sungai $(B) 40 \mathrm{~m}$, diperoleh tinggi sabo dam $(H) 10 \mathrm{~m}$.

Perencanaan dimensi pelimpah diawali dengan perhitungan kedalaman aliran saat terjadi banjir maupun aliran debris. Kedalaman aliran dianalisis untuk memperhitungkan tinggi jagaan pada pelimpah dan mengantisipasi supaya tidak terjadi limpasan air pada pelimpah ketika banjir maupun aliran debris. Kedalaman 
aliran debris dihitung menggunakan persamaan berikut.

$h_{d}=\left[\frac{n Q_{s p}}{B(\sin \theta)^{0,5}}\right]$

dengan $(\theta)$ adalah kemiringan dasar sungai dalam satuan derajat dan $h_{d}$ adalah kedalaman aliran debris. Berdasarkan persamaan tersebut diperoleh nilai kedalaman aliran debris sebesar $1 \mathrm{~m}$.

Perencanaan kedalaman pelimpah sabo dam memperhitungkan kedalaman aliran debris dan tinggi jagaan normal berdasarkan standar dari JICA (2010). Berdasarkan hasil hitungan nilai debit banjir rencana $\left(Q_{p}\right)$ diperoleh sebesar 114,14 $\mathrm{m}^{3} /$ det dan debit puncak aliran debris $\left(Q_{s p}\right)$ sebesar 228,28 $\mathrm{m}^{3} /$ det. Standar JICA (2010) menetapkan untuk debit banjir rencana kurang dari $200 \mathrm{~m}^{3} /$ det, nilai tinggi jagaan yang digunakan adalah 0,6 m. Kedalaman pelimpah sabo dam dihitung menggunakan persamaan berikut.

$Q=\left(0,71 \times h_{1}+1,77 \times B\right) \times h_{1}^{\frac{3}{2}}$

Dengan metode trial-error, tetapkan lebar rerata sungai $(B)$ dan nilai $h_{1}$ yang memenuhi persamaan (2). Kemudian dari hasil tersebut diperoleh kedalaman limpasan $\left(h_{1}\right)$ 1,8 m. Kedalaman pelimpah total $\left(h_{t}\right)$ disyaratkan harus lebih besar dari kedalaman aliran debris $\left(h_{d}\right)$. Kedalaman pelimpah harus melebihi kedalaman aliran debris untuk mengantisipasi terjadinya limpasan pada saat banjir maupun aliran debris. Kedalaman pelimpah sabo dam ditentukan berdasarkan kedalaman aliran saat banjir dan debris. Selain itu, perlu diberi tinggi jagaan sebagai bentuk preventif terhadap faktor ketidakpastian dari besarnya debit aliran debris. Berdasarkan pertimbangan di atas, kedalaman pelimpah direncanakan 2,4 $\mathrm{m}$ yang merupakan hasil penjumlahan kedalaman limpasan dengan tinggi jagaan yang disyaratkan.
Lebar pelimpah umumnya tergantung pada lebar rerata sungai $(B)$ dan debit aliran puncak debris $\left(Q_{s p}\right)$. Posisi pelimpah harus mempertimbangkan arah alur sungai, karena aliran debris cenderung mengalir lurus dan kekuatan aliran debris sangat besar sehingga mampu mengikis tebing sungai. Posisi pelimpah harus mampu mengarahkan aliran tetap berada di alur sungai. Oleh karena itu, bentuk pelimpah dibuat trapesium yang dilengkapi dengan perpanjangan struktur di sisi kiri dan kanan pelimpah sepanjang 20 m (JICA, 2010).

Tebal pelimpah pada sabo dam ditentukan berdasarkan gradasi material debris dengan mempertimbangkan kemungkinan kerusakan akibat benturan dan abrasi oleh aliran debris. Pelimpah harus memiliki tahanan yang baik terhadap gaya pukul (impact) sedimen/debris maupun gerusan batu-batu yang melewatinya. Dasar pelimpah sabo dam dirancang sedemikian rupa agar tidak terjadi konsentrasi aliran debris. Mengacu pada standar (JICA, 2010), tebal pelimpah sabo dam $\left(b_{1}\right)$ didesain setebal $3 \mathrm{~m}$ karena material-material debris yang melewati alur Sungai Air Kotok didominasi oleh batu-batu dan pasir.

Bukaan pada sabo dam tipe conduit dapat melewatkan aliran normal sepanjang tahun, aliran banjir maupun aliran debris yang tidak begitu deras. Di samping itu bukaan sabo dam mampu mengalirkan kembali material pasir dan kerikil ke hilir ketika aliran normal untuk menjaga keseimbangan sedimen agar tidak terjadi degradasi dasar sungai.

Bentuk bukaan sabo dam dapat bermacammacam tergantung pada pola alur sungai. Pada hulu dan hilir Sungai Air Kotok pola alur sungainya membentuk "V", sehingga digunakan bentuk bukaan sejajar. Jumlah bukaan dan dimensi sabo dam dicoba-coba (trial) sampai mendapatkan dimensi dan jumlah bukaan yang optimal. Dimensi bukaan dipengaruhi oleh lebar pelimpah dan tinggi sabo dam. Dimensi bukaan sabo dihitung menggunakan persamaan berikut. 


$$
Q=\frac{2}{15} C \sqrt{2 g} \times(3 b+2 b) \times h_{c}^{\frac{3}{2}}
$$

Jumlah bukaan ditetapkan sebanyak 6 buah, $C$ merupakan nilai koefisien debit pelimpah sebesar 0,6 (SNI 2415:2016), lebar bukaan $(b)$ dicoba $2 \mathrm{~m}$ dan tinggi bukaan $\left(h_{c}\right)$ 4,7 $\mathrm{m}$. Dari persamaan (7) diperoleh tinggi aliran air saat terjadi banjir maupun aliran debris sedalam $4 \mathrm{~m}$, sehingga tinggi bukaan yang direncanakan aman dari limpasan.

Struktur sabo dam bagian hulu akan terbentur material debris terutama boulder, sehingga sisi hulu sabo dam harus memiliki struktur yang kokoh. Diameter boulder pada lokasi kajian berkisar 1,5 m. Kemiringan bagian hulu $(m)$ sabo dam dicoba-coba untuk mencapai stabilitas yang disyaratkan agar sabo dam tidak mengalami keruntuhan geser dan guling. Kemiringan hulu sabo dam $(m)$ ditentukan sebesar 0,4 dan kemiringan hilir $(n) 0,3$.

Tinggi sub dam didesain $1 / 3$ dari tinggi sabo dam. Lebar dasar sub dam ditentukan oleh hasil analisa dan perhitungan stabilitas serta daya dukung tanah, yaitu setebal $2 \mathrm{~m}$. Agar tidak terjadi gerusan dan penurunan pada dasar sungai, maka bentuk dan kedalaman pelimpah sub dam didesain mengikuti desain sabo dam.

Apron dibuat untuk melindungi sabo dam dan sub dam dari potensi gerusan lokal di hilir, menjaga stabilitas fondasi sabo dam, dan melindungi terhadap runtuhnya kedua tebing sungai. Apron harus direncanakan kuat terhadap benturan batu-batu yang jatuh dari pelimpah sabo dam. Panjang apron akan mempengaruhi pengaruh rembesan, semakin panjang lintasan apron maka semakin kecil potensi rembesan. Lebar apron sama dengan lebar pelimpah atau lebih besar supaya aliran tidak menyempit. Pada bagian ujung hilir lebar apron mengecil, supaya aliran mengarah ke tengah sungai. Tebal apron didesain untuk mampu menahan energi aliran atau loncatan air, karena energi aliran dilepas di apron. Berdasarkan standar JICA (2010), untuk tinggi sabo dam $10 \mathrm{~m}$, maka tebal apron yang dipersyaratkan adalah 1,5 m dan panjang apron ditentukan $18 \mathrm{~m}$. Dimensi sabo dam yang direncanakan ditunjukkan pada Gambar 4 dan Gambar 5.

Dinding tepi (revetment) berfungsi melindungi tebing-tebing sungai terhadap longsoran maupun erosi oleh aliran arus sungai dan sebagai pengarah arus sungai. Dinding tepi didesain pada kedua sisi tebing di bagian apron. Dinding tepi didesain setinggi $3 \mathrm{~m}$.

\section{Analisis Stabilitas Sabo Dam}

Analisis stabilitas bangunan sabo dam mempertimbangkan gaya-gaya eksternal yang bekerja pada sabo dam. Analisis yang dilakukan untuk meninjau stabilitas eksternal struktur berdasarkan tipe potensi keruntuhan, yaitu stabilitas geser, stabilitas guling, dan daya dukung tanah. Metode analisis yang digunakan mengacu pada SNI 2851:2015. Adapun gaya-gaya yang bekerja pada sabo dam ditunjukkan pada Gambar 6 dan Gambar 7. 
Desain Sabo Dam... (Yuli/ hal 105-116)
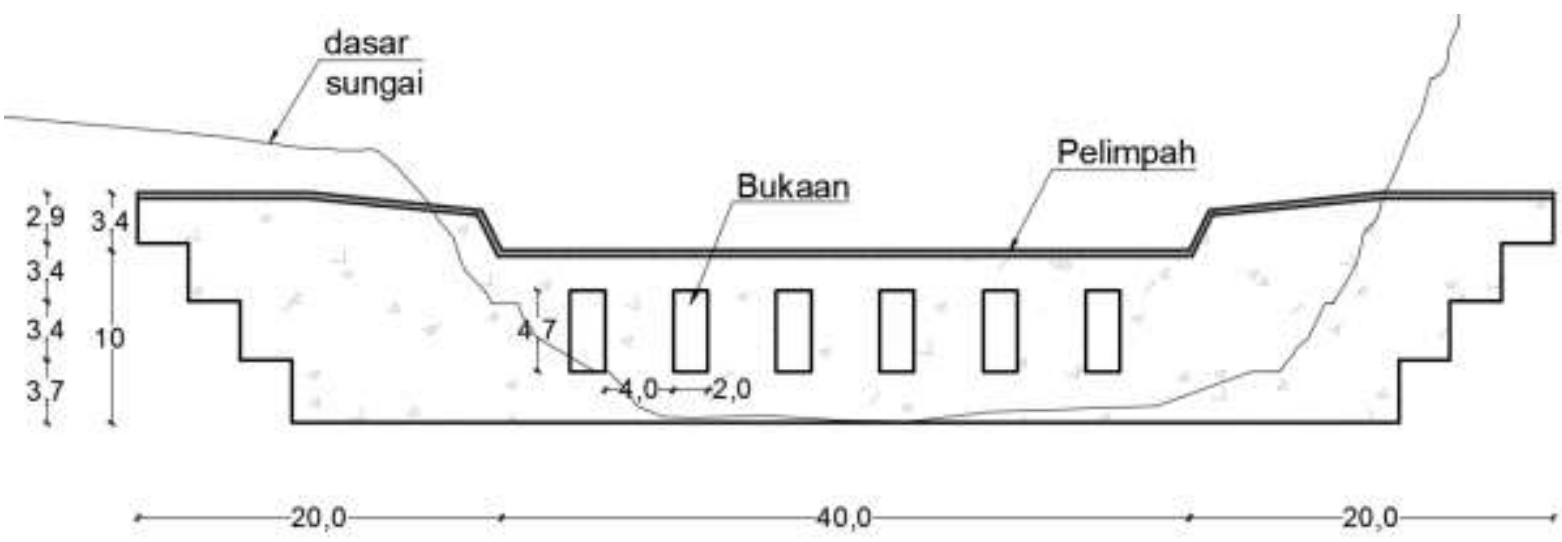

Gambar 4. Tampak Melintang Sabo Dam

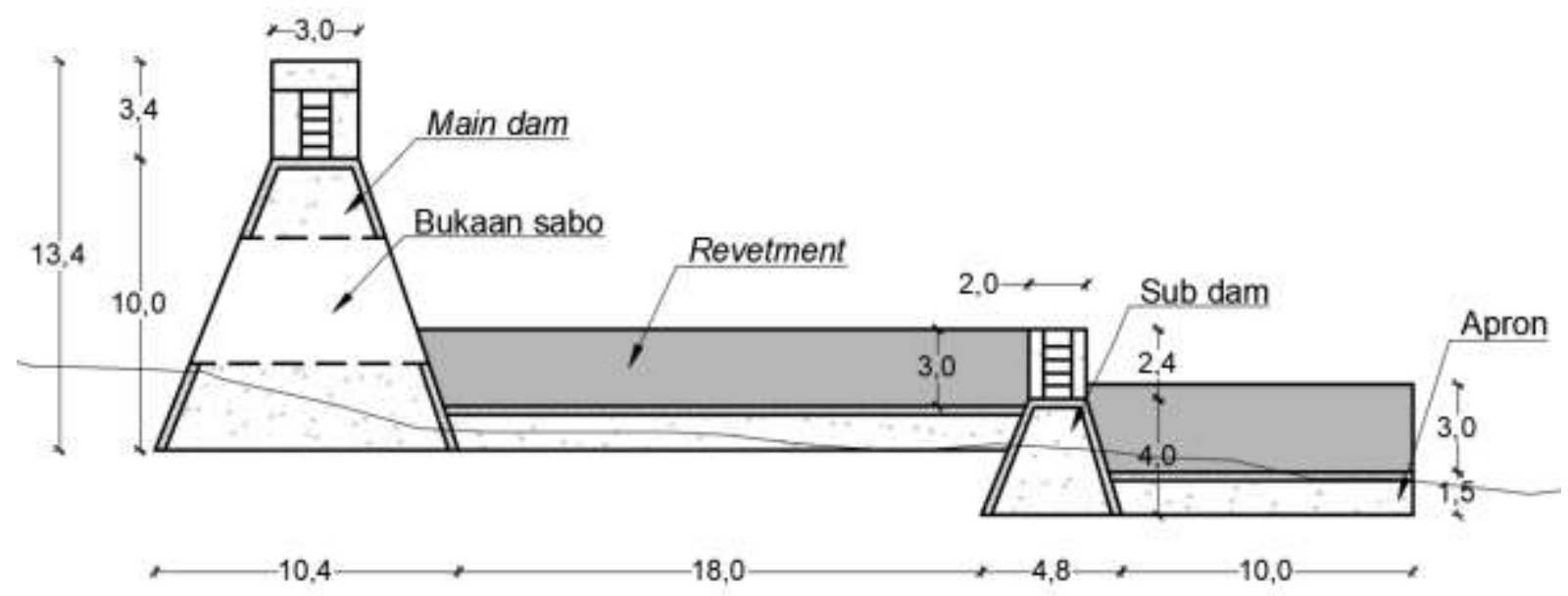

Gambar 5. Tampak Memanjang Sabo Dam

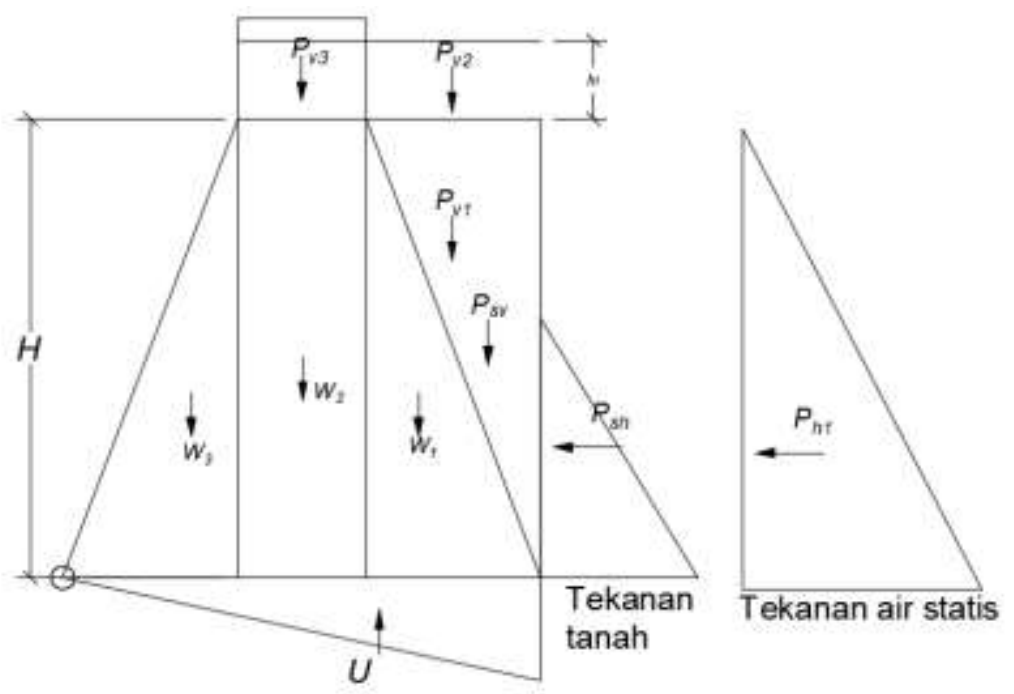

Gambar 6. Gaya-gaya Eksternal Sabo Dam Pengaruh Banjir 


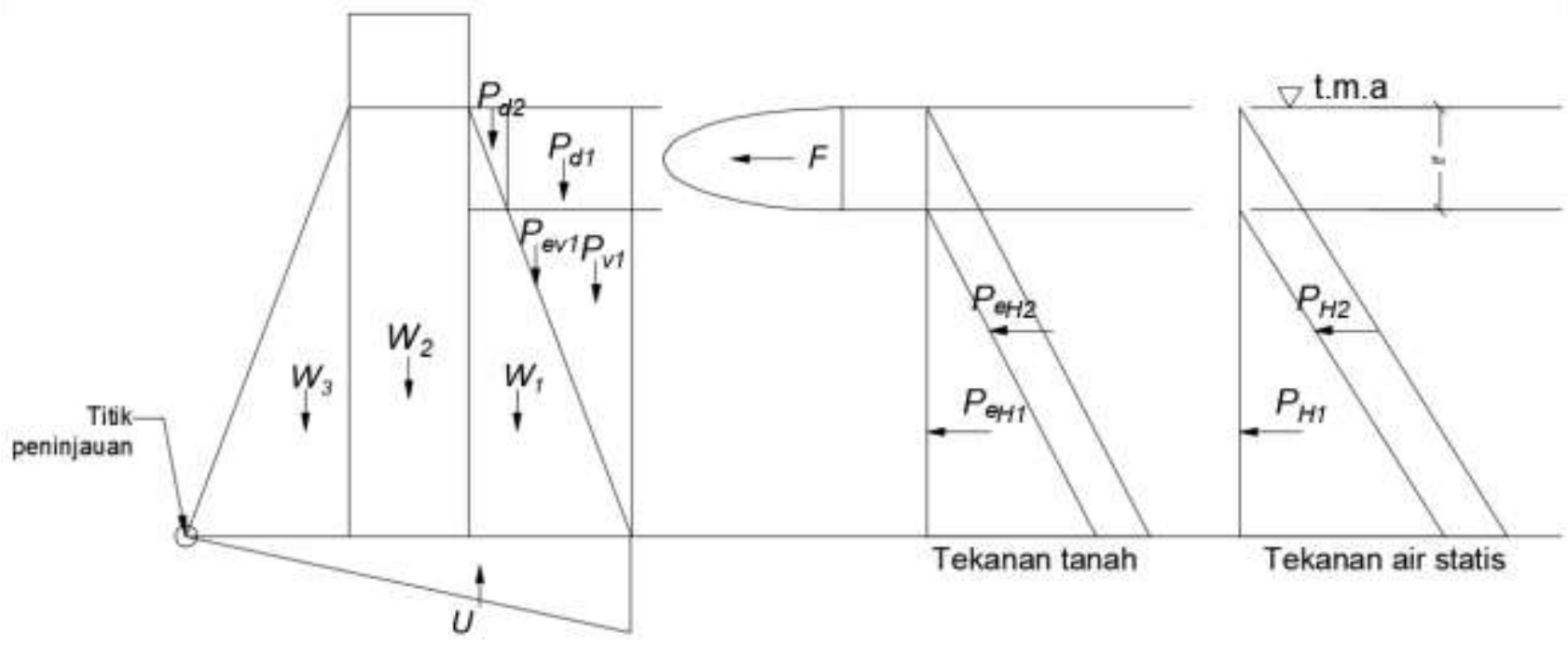

Gambar 7. Gaya-gaya Eksternal Sabo Dam Pengaruh Aliran Debris

Tabel 1. Hasil Perhitungan Gaya dan Momen Pada Sabo Dam akibat Pengaruh Banjir

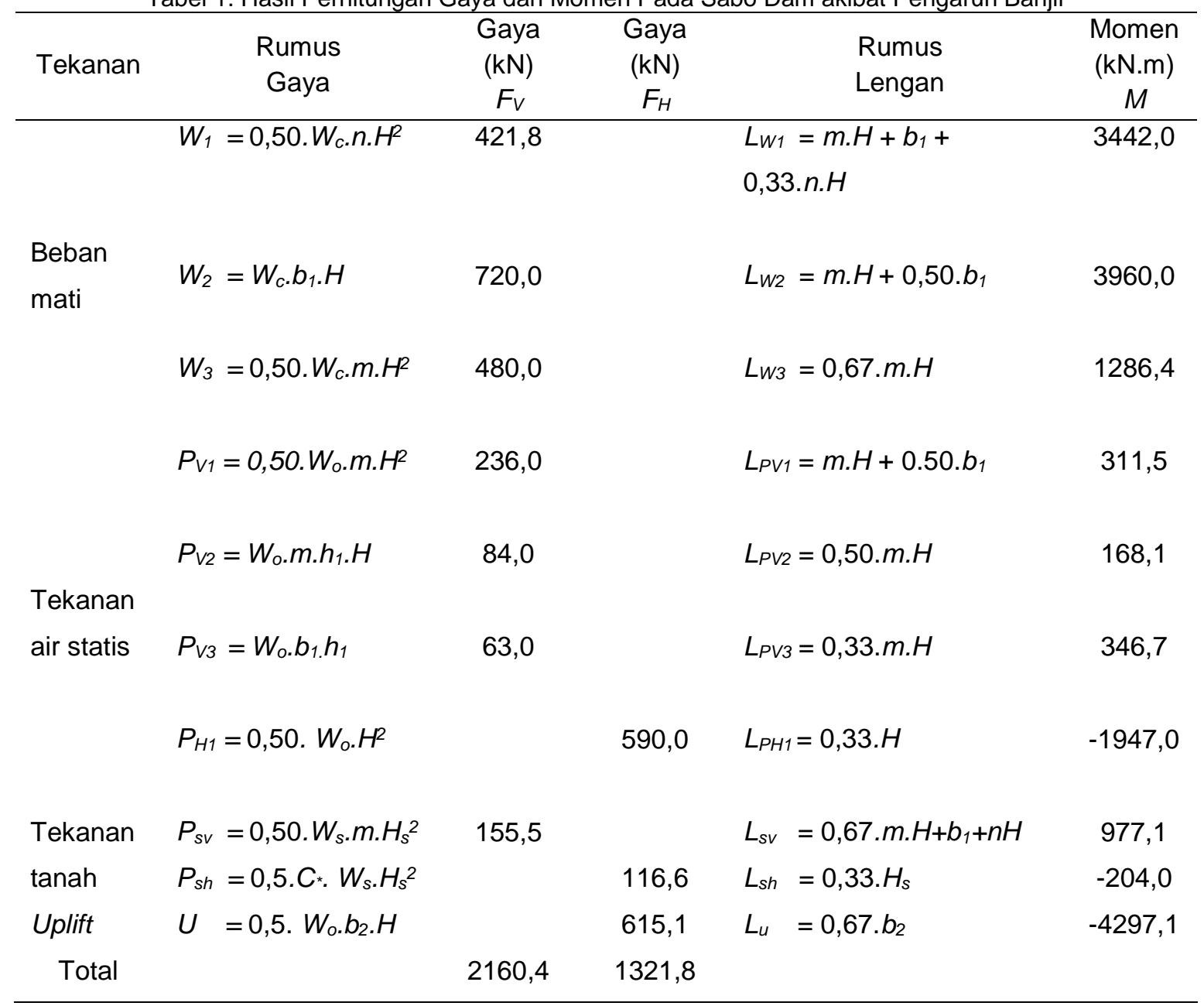

Berdasarkan Tabel 1, nilai berat jenis beton $\left(W_{c}\right) 24 \mathrm{kN} / \mathrm{m}^{3}$, berat jenis air $\left(W_{o}\right)$ untuk tinggi sabo dam kurang dari $15 \mathrm{~m}$ sebesar $9,8 \mathrm{kN} / \mathrm{m}^{3}$, berat jenis debris $\left(W_{s}\right)$ menurut
Huang dkk. (2003) sebesar $27,7 \mathrm{kN} / \mathrm{m}^{3}$. Tebal pelimpah bagian atas $\left(b_{1}\right) 3 \mathrm{~m}$ dan lebar dasar sabo dam $\left(b_{2}\right)$ sebesar 10,4 m, tinggi endapan sedimen $\left(H_{s}\right)$ 5,3 m. 
a. Stabilitas geser pengaruh banjir Keruntuhan akibat geser terjadi karena adanya gaya pendorong dan gaya penahan yang bekerja. Gaya penahan berupa tekanan hidrostatis, berat sendiri sabo dam, dan tekanan tanah. Gaya pendorong berupa gaya hidrostatis arah horizontal, tekanan tanah arah horizontal, dan uplift. Persamaan untuk menghitung faktor aman terhadap tahanan geser adalah sebagai berikut.

$S F=\frac{f F_{V}+\tau \ell}{F_{H}}$

Berdasarkan SNI 2851:2015, nilai koefisien geser pada bidang kontak $(f)$ untuk jenis tanah keras sebesar 0,7 dan nilai tegangan geser $(\tau) 294 \mathrm{kN} / \mathrm{m}^{2}$, serta panjang tahanan geser $\left(\ell=b_{2}\right) \quad 10,4 \mathrm{~m}$. Berdasarkan persamaan (8) diperoleh faktor aman tahanan geser 3,46 .

Keruntuhan terhadap geser dapat terjadi apabila gaya pendorong lebih besar daripada gaya penahan. Nilai rasio minimum antara gaya pendorong dan gaya penahan agar diperoleh kondisi sabo dam stabil adalah 2,0. Pada kondisi ini, sabo dam mampu mempertahankan kedudukannya dalam kondisi diam.

b. Stabilitas guling pengaruh banjir Kegagalan akibat guling pada struktur dapat terjadi dikarenakan adanya momen yang bekerja pada struktur tersebut tidak seimbang. Momen ditimbulkan dari gayagaya yang bekerja dikali dengan lengannya terhadap titik pusat guling. Jarak antara titik resultan gaya dapat dijadikan acuan dalam

analisis stabilitas terhadap guling. Persamaan untuk menghitung faktor aman terhadap guling:

$S F=\frac{M_{v}}{M_{H}}$

Keruntuhan terhadap guling dapat terjadi apabila momen pendorong lebih besar daripada momen penahan. Nilai rasio minimum antara momen pendorong dan momen penahan agar diperoleh kondisi sabo dam stabil adalah 1,5. Berdasarkan hasil perhitungan didapat faktor aman 1,62 $(S F>1,5)$ yang menyatakan kondisi struktur stabil terhadap guling pada kondisi banjir.

Tabel 2. Hasil perhitungan gaya dan momen pada sabo dam akibat pengaruh aliran debris

\begin{tabular}{|c|c|c|c|c|c|}
\hline $\begin{array}{l}\text { Gaya/ } \\
\text { Tekanan }\end{array}$ & $\begin{array}{l}\text { Rumus } \\
\text { Gaya }\end{array}$ & $\begin{array}{c}\text { Gaya } \\
(\mathrm{kN}) \\
F_{V}\end{array}$ & $\begin{array}{c}\text { Gaya } \\
(\mathrm{kN}) \\
F_{H}\end{array}$ & $\begin{array}{l}\text { Rumus } \\
\text { Lengan }\end{array}$ & $\begin{array}{c}\text { Momen } \\
(\mathrm{kN} \cdot \mathrm{m}) \\
M\end{array}$ \\
\hline \multirow{3}{*}{$\begin{array}{l}\text { Beban } \\
\text { mati }\end{array}$} & $W_{1}=0,50 \cdot W_{c} \cdot n \cdot H^{2}$ & 421,8 & & $L_{w 1}=m \cdot H+b_{1}+0,33 \cdot n \cdot H$ & 3442,0 \\
\hline & $W_{2}=W_{c} \cdot b_{1} \cdot H$ & 720,0 & & $L_{w 2}=m \cdot H+0,50 \cdot b_{1}$ & 3960,0 \\
\hline & $W_{3}=0,50 \cdot W_{c} \cdot m \cdot H^{2}$ & 480,0 & & $L_{w_{3}}=0,67 \cdot m \cdot H$ & 1286,4 \\
\hline \multirow{3}{*}{$\begin{array}{l}\text { Tekanan } \\
\text { air statis }\end{array}$} & $P_{V 1}=0,50 \cdot W_{o} \cdot m\left(H-h_{d}\right)^{2}$ & 193,6 & & $L_{P V 1}=0,67 \cdot m \cdot(H-$ & 1493,2 \\
\hline & $P_{H 1}=0,50 \cdot W_{o}\left(H-h_{d}\right)^{2}$ & & 484,1 & $L_{P H 1}=0,33 .\left(H-h_{d}\right)$ & $-1447,2$ \\
\hline & $P_{H 2}=W_{o} \cdot h_{d}\left(H-h_{d}\right)$ & & 100,6 & $L_{P H 2}=0,50 .\left(H-h_{d}\right)$ & $-455,9$ \\
\hline \multirow{4}{*}{$\begin{array}{l}\text { Tekanan } \\
\text { tanah }\end{array}$} & $P e_{V 1}=0,50 \cdot W_{e} \cdot m \cdot\left(H-h_{d}\right)^{2}$ & 51,2 & & $\begin{array}{l}L_{P e V 1}=0,33 \cdot m \cdot(H- \\
\left.h_{d}\right)+b_{1}+n H\end{array}$ & 395,1 \\
\hline & $P e_{H 1}=0,50 \cdot W_{e} \cdot m \cdot\left(H-h_{d}\right)^{2}$ & & 51,2 & $L_{P e H 1}=0,33 \cdot\left(H-h_{d}\right)$ & $-153,2$ \\
\hline & $P e_{H 2}=C_{d \cdot} \cdot \rho_{f} m \cdot h_{d} \cdot\left(H-h_{d}\right)^{2}$ & & 31,3 & $L_{P e H 2}=0,50 \cdot\left(H-h_{d}\right)$ & $-141,9$ \\
\hline & $P_{d 1}=\rho_{d \cdot} \cdot h_{d \cdot} \cdot m \cdot\left(H-h_{d}\right)$ & 51,8 & & $L_{P d 1}=0,50 \cdot m \cdot\left(H-h_{d}\right)+b_{1}+n H$ & 431,3 \\
\hline
\end{tabular}


Desain Sabo Dam... (Yuli/ hal 105-116)

\begin{tabular}{|c|c|c|c|c|c|c|}
\hline $\begin{array}{l}\text { Berat } \\
\text { aliran } \\
\text { debris }\end{array}$ & $P_{d 2}$ & $=0,5 \cdot \rho_{d} \cdot m \cdot h_{d}^{2}$ & 2,7 & & $L_{P d 2}=m \cdot\left(H-h_{d}\right)+b_{1}+n H$ & 27,3 \\
\hline $\begin{array}{l}\text { Tekanan } \\
\text { air aliran } \\
\text { debris }\end{array}$ & $F$ & $=\left(\rho_{d} / g\right) h_{d} \cdot v_{d}^{2}$ & & 53,6 & $L_{F}=0,50 . h_{d}+\left(H-h_{d}\right)$ & $-510,5$ \\
\hline \multirow[t]{2}{*}{ Uplift } & $U$ & $=0,5 \cdot W_{o} \cdot b_{2} \cdot H$ & & 615,1 & $L_{u}=0,67 \cdot b_{2}$ & $-4297,1$ \\
\hline & & Total & 1921,2 & 1336,1 & Total & 18041 \\
\hline
\end{tabular}

Berdasarkan Tabel 2, berat jenis sedimen $\left(W_{e}\right)$ sebesar $9,1 \mathrm{kN} / \mathrm{m}^{3}$, berat jenis campuran pasir dan kerikil $\left(\rho_{t}\right)$ sebesar 3,4 $\mathrm{kN} / \mathrm{m}^{3}$, berat jenis aliran debris $\left(\rho_{d}\right)$ sebesar $15,2 \mathrm{kN} / \mathrm{m}^{3}$. Kecepatan aliran debris $\left(v_{d f}\right) 6$ $\mathrm{m} /$ det.

\section{a. Stabilitas geser pengaruh aliran debris}

Stabilitas geser terhadap kondisi debris yang dievaluasi dengan membandingkan gaya pendorong dan gaya penahan yang bekerja. Gaya penahan berupa tekanan hidrostatis, panjang tahanan geser, koefisien geser, dan tegangan geser lapisan tanah. Gaya pendorong berupa gaya hidrostatis arah horizontal, tekanan debris, dan uplift. Berdasarkan hasil perhitungan diperoleh faktor aman tahanan geser 3,3.

\section{b. Stabilitas guling pengaruh debris}

Dari analisis stabilitas terhadap guling pada kondisi debris diperoleh hasil perhitungan faktor aman sebesar 1,58. Nilai rasio minimum antara momen pendorong dan momen penahan agar diperoleh kondisi sabo dam stabil adalah 1,5. Berdasarkan hasil perhitungan didapat faktor aman 1,58 $(S F>1,5)$ yang menyatakan kondisi struktur stabil terhadap guling pada sabo dam.

\section{SIMPULAN}

Desain sabo dam di Sungai Air Kotok dirancang seri dengan 4 buah bangunan sabo dam yang memiliki tinggi dam $10 \mathrm{~m}$ dan mampu menampung volume debris sebanyak $40.000 \mathrm{~m}^{3}$, serta lebar pelimpah sesuai dengan lebar rerata dasar sungai yaitu $40 \mathrm{~m}$. Kedalaman aliran debris untuk kala ulang 100 tahun adalah $1 \mathrm{~m}$, sehingga kedalaman pelimpah yang direncanakan adalah 2,4 m agar mampu melewatkan debit banjir rencana dan debit aliran debris. Sabo dam conduit didesain memiliki 6 bukaan dengan tinggi bukaan $4,7 \mathrm{~m}$ dan lebar $2 \mathrm{~m}$.

Hasil analisis stabilitas sabo dam conduit untuk pengaruh banjir diperoleh faktor aman terhadap stabilitas geser sebesar 3,46, faktor aman terhadap stabilitas guling sebesar 1,62, dan stabilitas daya dukung sebesar 871,23 kN/m. Hasil analisis stabilitas akibat pengaruh aliran debris diperoleh faktor aman terhadap stabilitas geser sebesar 3,30 dan faktor aman terhadap stabilitas guling sebesar 1,58, serta stabilitas daya dukung $871,23 \mathrm{kN} / \mathrm{m}$.

\section{DAFTAR RUJUKAN}

Armanini, A., Dalri, C. \& Larcher, M. 2014. Slitcheck dams for controlling debris flow and mudflow. Disaster Mitigation of Debris Flows, Slope Failures and Landslides, (July): 141-148.

Fathani, T.F. \& Wilopo, W. 2018. Kajian Potensi Aliran Debris. Yogyakarta:Universitas Gadjah Mada.

Hardiyatmo, H.C. 2011. Analisis dan Perancangan Fondasi 1. Gadjah Mada University Press.

Hardiyatmo, H.C. 2012. Penangan tanah longsor \& erosi. Gadjah Mada University Press.

Hassan, C. 2019. Perencanaan Sabo dam Modular. Balai Litbang Sabo. 
Hidayat, N., Pratama, G. N. I. P., \& Pramita, I. D. (2019, November). The Effect of PET Plastic Addition (Polyethylene Terephthalate) and Carbide Waste Filler for Asphalt Concrete-Binder Course (AC$\mathrm{BC})$ on Marshall Characteristics. In IOP Conference Series: Earth and Environmental Science (Vol. 366, No. 1, p. 012024). IOP Publishing.

Huang, H., Yang, K. \& Lai, S. 2003. Impact force of debris flow on filter dam.

JICA 2010. Technical Standards and Guidelines for Planning and Design of Sabo Structure.

Kim, N., Nakagawa, H., Kawaike, K. \& Zhang, H. 2014. A study on debris flow outflow discharge at a series of sabo dams. 43-52.

Ministry of Land Infrastructure and Transport Development of Japan 2004. Guidelines for construction technology transfer.

Pratama, G. N. I. P. P., \& Najihan, H. F. (2020, September). The Effect of Beach Sands to Replacement of Fine Aggregate with Addition Filler of Ash Cane on the Asphalt Mixture on Marshall Characteristics. In Journal of Physics: Conference Series (Vol. 1625, No. 1, p. 012032). IOP Publishing.

Pratama, G. N. I. P., \& Sumarjo, H. (2018). Aksesibilitas Tata Letak Elevator Penumpang Gedung Kantor Pusat Layanan Terpadu (KPLT) Fakultas Teknik UNY. INformasi dan Ekspose hasil Riset Teknik SIpil dan Arsitektur, 14(1), 26-35.

Pusat Penelitian dan Pengembangan Sumber Daya Air 2014. Stabilitas Pondasi Mengambang pada Bangunan Sabo.

SNI 1724:2015 2015. Analisis hidrologi, hidraulik, dan kriteria desain bangunan di sungai.

SNI 2415:2016 2016. Tata cara perhitungan debit banjir rencana.

SNI 2851:2015 2015. Desain bangunan penahan sedimen.

Takahashi, T. 2007. Debris flow Mechanics, Prediction and Countermeasures. Taylor \& Francis.

Turnbull, B., Bowman, E.T. \& McElwaine, J.N. 2015. Debris flows: Experiments and modelling. Comptes Rendus Physique,
16(1): 86-96.

Zou, Y.H. \& Chen, X.Q. 2015. E ff ectiveness and e ffi ciency of slot-check dam system on debris flow control. Natural Hazards and Earth System Science, 3: 5777-5804. Tersedia di www.nat-hazards-earth-systsci-discuss.net/3/5777/2015/. 